\title{
Vigencia y perspectivas de la investigación participativa
}

Alfonso Torres Carrillo Doctor en Estudios Latinoamericanos, UNAM. Profesor de la Universidad Pedagógica Nacional, actualmente, Coordinador de la Maestría en Estudios Sociales. e-mail: alfonsitorres@yahoo.es

Conferencia en UNIMINUTO, abril 21 de 2009.

A Orlando Fals Borda y Germán Zabala, in memoriam

Las propuestas y enfoques de investigación que se plantean involucrar a la población de base en la producción de conocimiento sobre su propia realidad con el objeto de transformarla desde intenciones emancipadoras' surgieron y se expandieron en el contexto social y políitico de América Latina en las décadas de los setenta y ochenta (Gajardo, 1994). Podría conjeturarse que, reconocidos los múltiples cambios intelectuales y sociopolíticos que han

`VIO GROSSI, Francisco. "La investigación participativa: contexto político y organización popular". En: Arco Iris, Santiago de Chile :CEAAL, 1993, pág.131. 
acontecido en las dos últimas décadas de la historia reciente, dicho enfoque investigativo crítico ha perdido vigencia epistemológica y política. Nada más alejada de la verdad; con el siguiente artículo quiero demostrar cómo buena parte de las discusiones contemporáneas en el campo de la epistemología, el pensamiento crítico, las ciencias sociales y la investigación encuentran grandes confluencias con la IAP.

Para sustentar mi argumentación, me basaré en publicaciones recientes acerca de las tendencias y planteamientos epistemológicos e investigativos actuales, en particular, autores como Boaventura de Sousa Santos, Jesús Ibáñez y Hugo Zemelman, así como en libros como La nueva producción del conocimiento, La dinámica de la ciencia y la investigación en las sociedades contemporáneas de varios autores (1997) e Indisciplinar las ciencias sociales de Catherine Walsh, Freda Schiwy y Santiago Castro (2002), así como en las Memorias del Congreso mundial de convergencia en investigación participativa (Cartagena, 1997) y en mis propias reflexiones acerca del tema (2000, 2008 y 2009).

En primer lugar, en la actualidad hay un relativo consenso acerca de los límites del paradigma occidental de la ciencia clásica, dado que impiden comprender la realidad en su complejidad y construir o reconocer otros mundos posibles ("transformar la realidad"). Edgar Morin denomina a ésta matriz epistémica clásica como "paradigma de simplicidad", que supone orden en el universo y persigue o excluye el desorden; que reduce el orden a una ley, a un principio; que evitando la contradicción, el azar, reduce la complejidad del mundo; que expulsa la subjetividad del conocimiento, reduciéndola a abstracción y privilegia la lógica instrumental en la investigación.
En ese contexto, Santos plantea que es necesario reinventar las ciencias porque hoy son parte del problema, pero pueden ser parte de la solución. "Es decir, no es un problema de las ciencias sociales, sino de la racionalidad que subyace en ellas" ${ }^{\prime 2}$. A esa racionalidad la denomina "insolente", "perezosa", dado que reduce el campo de realidad a lo dado, a lo existente.

Con respecto al primer libro resultado de un trabajo conjunto de seis científicos destacados provenientes de Inglaterra, Canadá, Austria, Brasil y Estados Unidos y que pretende dar cuenta de la política del conocimiento científico en su más amplio contexto dentro de las sociedades contemporáneas, constatan que estamos asistiendo a cambios fundamentales en la producción del conocimiento científico, social y cultural. El nuevo modo de producción de conocimiento (llamado por ellos Modo dos) está sustituyendo o reformando las instituciones, disciplinas, prácticas y políticas académicas establecidas y al que estamos familiarizados (Modo uno).

Simplificando, los autores destacan los siguientes rasgos del emergente Modo dos:

1. El conocimiento es producido en contextos dinámicos de aplicación

No se trata tanto de la definición de problemas dentro de la lógica de las disciplinas en particular sino en torno a la solución de problemas concretos; no se trata de conocimiento básico aplicado sino de que el conocimiento demandado sea útil para alguien, sea la industria, el gobierno o grupos sociales específicos,

${ }^{2}$ SANTOS, Boaventura de Sousa. La caída del angelus novus. Ensayos para una nueva teoría social y una nueva práctica política. Bogotá: ILSA - Universidad Nacional de Colombia, 2003, pág. 20. 

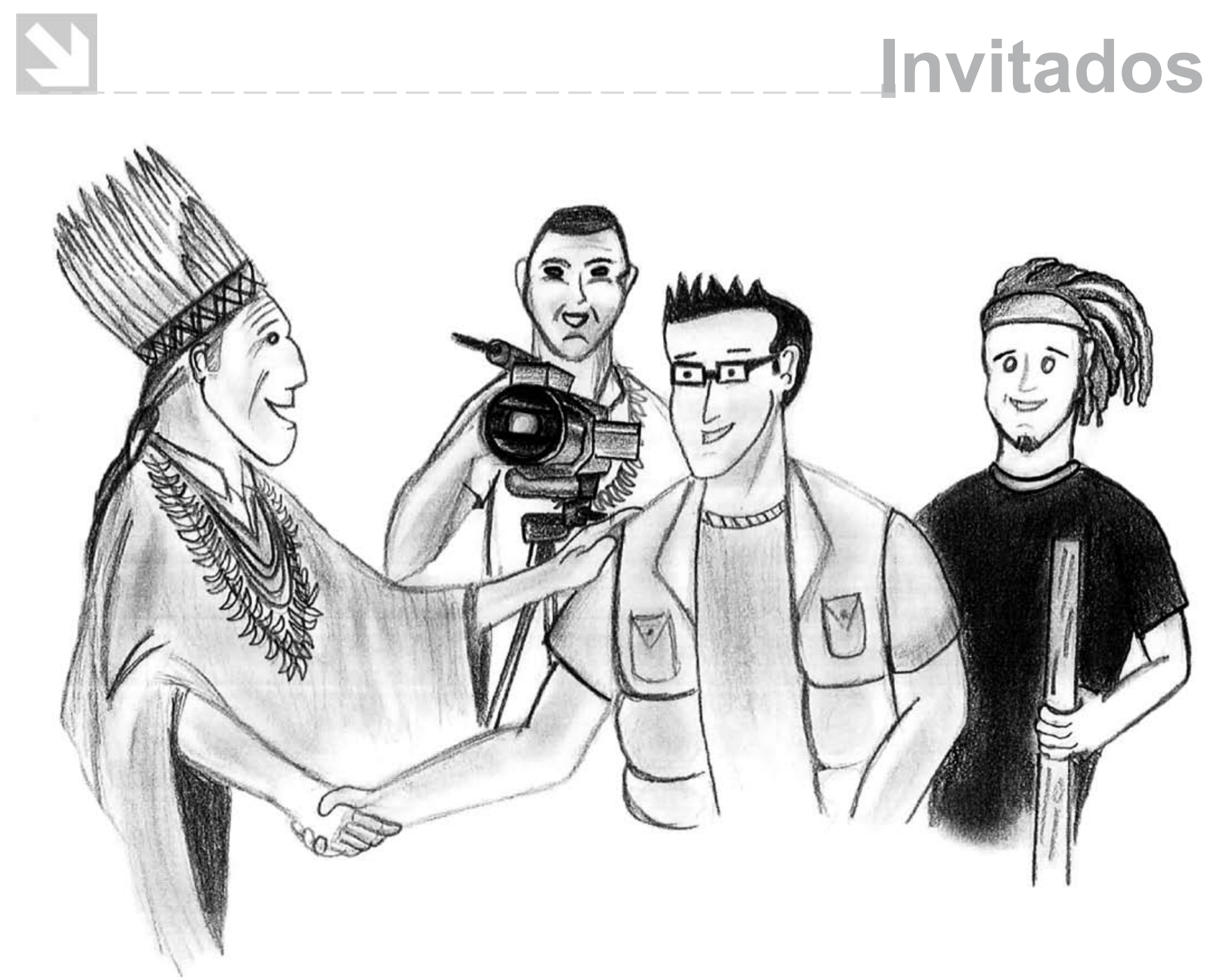

ello implica una negociación continua con otros actores "no académicos".

Esta conexión entre conocimiento y acción es una de las características de la IAP, en la medida en que reconoce el interés práctico de todo conocimiento y la necesaria proyección social del conocimiento en función de las demandas y problemas de los amplios sectores sociales marginados del poder. Por ello, valoro la categoría "praxis", entendida como la reflexión permanente y crítica sobre las prácticas sociales ${ }^{3}$.

${ }^{3}$ FALS BORDA, Orlando. El problema de cómo investigar la realidad para transformarla por la praxis. Bogotá: Tercer Mundo editores, 1984. 
Esta generación de conocimiento en contextos de aplicación tampoco es ajena a las tecnologías e ingenierías que aunque históricamente se establecieron en las universidades hace más de medio siglo, pero que más que "ciencia aplicada" son genuinas formas de producción de conocimiento que hoy incluso contribuyen al desarrollo de las ciencias básicas.

\section{Transdiciplinaridad}

El modo dos es algo más que el trabajo colaborativo de especialistas en torno a la solución de problemas específicos; la investigación en contexto requiere construir consensos específicos en torno a sus presupuestos conceptuales, sus prácticas metodológicas y sus implicaciones extracognitivas. La transdiciplinaridad, a diferencia de la multi e interdisciplinariedad implica una verdadera creatividad, pues articula teorías, métodos y procedimientos provenientes de las disciplinas pero en función de la especificidad de los problemas a resolver. Ello implica trabajo en equipo, permanente diálogo y sensibilidad al contexto; por ello, la comunicación de los resultados no está dirigida a las comunidades disciplinares sino a aquellos que han participado en la investigación y a las poblaciones que se beneficiarán con ellos.

La IAP desde sus inicios proclamó la necesaria complementariedad entre el conocimiento de expertos, generalmente provenientes de las ciencias y profesiones, y el saber popular; pero también entre el pensamiento y el sentimiento, entre la lógica analítica y la lógica emocional, entre pensamiento analítico y pensamiento narrativo. En diferentes ocasiones, Fals Borda ha destacado que en los orígenes de las ciencias (naturales y sociales) se dio esta convergencia entre sabiduría popular y conocimiento académico (Linneo, Newton,
Edison) hasta que el positivismo y el neopositivismo los separaron tajantemente ciencia y saber común; la propuesta del diálogo de saberes, más que complementariedad entre disciplinas, implica una confluencia de lógicas, concepciones, estrategias y procedimientos diferentes en función de superar problemas concretos y mejorar la calidad de vida de la gente; también en la indisolubilidad del pensar y el sentir en el actuar y en la necesaria valoración de estas dos dimensiones humanas.

Desde la perspectiva gramsciana de convertir el sentido común popular en "buen sentido" ${ }^{4}$, ha insistido en enriquecer los esquemas interpretativos provenientes de la tradición y la cultura popular con la devolución sistemática y pedagógica de los resultados de la investigación entre los involucrados y entre la población interesada, acudiendo a diferentes lenguajes y formas expositivas, tanto argumentativas como narrativas. Dado el interés que pueda tener para los comunicadores aquí presentes, Fals Borda plantea para la "devolución sistemática" ${ }^{5}$ cuatro criterios:

a) Diferencial de comunicación, según los diferentes colectivos a los que se les quiere entregar los resultados: desde comics y materiales audiovisuales pasando por textos analíticos cortos hasta elaboraciones conceptuales para el mundo universitario.

b) Simplicidad de comunicación: uso de lenguajes sencillos, accesibles, lejanos de la terminología "complicada y esotérica" común entre los especialistas.

${ }^{4}$ lbid

5lbid, pág. 99 
c) Autoinvestigación y control: seguimiento reflexivo y permanente con las poblaciones partícipes de la investigación para "vigilar" la coherencia de las prácticas con los principios éticos, políticos y metodológicos del enfoque.

d) Uso de técnicas de investigación sencillas que las personas comunes y corrientes puedan comprender y emplear.

Para las ingenierías esta confluencia entre diferentes campos disciplinares y profesionales, así como entre saberes teóricos, metodológicos, técnicos y tecnológicos tampoco les es ajena: hasta donde conozco, en la Ingeniería Industrial confluyen conocimientos administrativos, de la teoría de sistemas, de la psicología industrial, entre otros.

\section{Heterogeneidad y diversidad organizativa}

Los retos del conocimiento dos no provienen tanto del balance crítico del saber acumulado por una disciplina sino de problemas desafiantes, muchas veces azarosos. En consecuencia, se caracteriza por la proliferación de lugares potenciales en los que se puede generar conocimiento más allá de las universidades y sus centros de investigación: centros de consultoría, laboratorios empresariales, instituciones de gobierno, las ONG. La vinculación entre estos nuevos ámbitos se da a través de diferentes redes de comunicación. Ello exige una flexibilidad en los modos de organización y en sus formas de trabajo; los grupos están menos institucionalizados, los equipos y redes son muchas veces temporales, los roles y distribución de responsabilidades son menos rígidas.

La IAP se presentó a sí misma como una ciencia modesta, hecha por intelectuales y gente del común no dentro ni para las universidades ni academias, sino en función del empoderamiento y emancipación de los sectores subalternos; por ello, se propuso la utilización de estrategias y técnicas flexibles y sencillas, así como de la valoración de los diversos lugares sociales en la producción de conocimiento: el barrio, la vereda, la fábrica y las organizaciones sociales.

\section{Responsabilidad y reflexividad social}

La creciente sensibilización de la opinión pública y la demanda en torno a temas relacionadas con el medio ambiente, la pauperización, las discriminaciones raciales y sexuales, etc., ha estimulado el crecimiento de la producción de conocimiento en el modo dos. Los científicos sociales trabajan junto a los científicos naturales, los ingenieros y abogados porque así lo exige la naturaleza de los nuevos problemas. Ello aumenta la sensibilidad de los científicos y tecnólogos. Hace que todos los participantes se vuelvan más reflexivos y se planteen interrogantes acerca de las implicaciones éticas y políticas de su trabajo, preocupaciones generalmente delegadas a las humanidades.

Esta relación entre conocimiento y compromiso de los profesionales ha sido un rasgo central de los enfoques participativos. La pretendida neutralidad de la ciencia proclamada por el positivismo ha sido cuestionada desde las ciencias crítico sociales. A partir del reconocimiento de la conexión saber/poder y del uso que se le ha dado a la ciencia y la tecnología al servicio de los intereses de los poderosos y del control social, los investigadores participativos han insistido en la necesidad de asumir posiciones críticas con estos usos opresivos del conocimiento y de reorientarlo hacia fines más altruistas y emancipadores. 


\section{Control social de calidad}

Mientras que en la ciencia disciplinar, el control de calidad es llevado a cabo exclusivamente por los pares académicos desde los parámetros, criterios y metodologías correspondientes a los paradigmas dominantes, en el modo dos se añaden otros actores y criterios de validez, de carácter económico, político y social. Esto no significa que la calidad alcanzada sea menor; por el contrario, los criterios son también pragmáticos, pues responden a interrogantes como: ¿será viable y rentable la propuesta?, ¿tendrá impacto social?, ¿contribuirá a fortalecer los procesos sociales en curso?

Pese a estar por fuera de toda racionalidad mercantil o gerencial, la IAP busca ser lo más significativa, pertinente, relevante y eficaz posible. La presencia de dichos principios en sus intervenciones no dependen tanto de la lógica disciplinar o profesional desde la que se interviene, sino de la capacidad de reconocer, articular y encauzar las dinámicas sociales y culturales de la población involucrada. La calidad de sus propuestas también es valorada en función de su capacidad de solucionar problemas prácticos y de fortalecer los procesos organizativos de los participantes de base.

El reconocimiento de la confluencia entre estas tendencias contemporáneas de la práctica científica de punta y la IP conlleva la reivindicación de ciertas exigencias del trabajo investigativo como son la creatividad, la apertura crítica (antidogmatismo), la capacidad innovativa, la participación y el compromiso social de los investigadores. De un modo u otro, la tradición investigativa ha reivindicado estos criterios de trabajo hoy tan apreciados.

Desde otra perspectiva, la de los desarrollos más recientes de la epistemología y la investigación social, pensa- dores como Jesús lbáñez (1997), Edgar Morin (1994) y Hugo Zemelman (2000) destacan algunas tendencias que están superando hoy varios de los presupuestos y supuestos de la ciencia clásica, subordinada según el primero a un paradigma de control e inspirada según Morin en un paradigma reduccionista según Zemelman en una racionalidad parametral. Frente al determinismo y la simplificación predominantes, estos autores destacan:

1. Indeterminismo, complejidad y relativismo tanto de la realidad como de los sujetos que la investigan.

2. Realidad social como construcción histórica, cultural, conversacional.

3. Exigencia de historicidad: investigar desde posicionamiento crítico frente al contexto.

\section{Pensareinvestigar desdeopciones detransformación.}

5. Conocimiento científico como sistema cultural "local" y por tanto interpretación de interpretaciones (hermenéutica).

6. Pensamiento crítico va más allá de lo cognitivo, involucra otras dimensiones subjetivas.

7. Principio de reflexividad, propio de los sistemas autoobservantes: observadores observados, fusión sujeto objeto de la investigación.

8. Superación de dicotomías (subjetivo/objetivo, teoría/práctica, lógica analítica/ lógica simbólica, $\mathrm{micro} / \mathrm{macro})$.

9. Perspectiva holística y complementariedad entre caos, orden y organización. 
10. Principio de complementariedad.

11. Apertura de las ciencias sociales a otros lenguajes y prácticas culturales.

12. Búsqueda de coherencia entre el pensar y el actuar.

Desde la propia reflexión de la IAP (Fals 1991 y 1997) se consideran vigentes los siguientes criterios equivalentes:

1. Validez de la construcción dialógica del conocimiento.

2. Privilegio de lo cualitativo sobre lo cuantitativo pero no su exclusión: valora subjetividad.

3. Investigación con responsabilidad social.

4. Investigador autónomo y crítico de los discursos del poder dominante.

5. Recuperación colectiva de la historia y la cultura popular y construcción de identidades subalternas.

\section{Combinación reflexión acción.}

7. La participación como principio ético y político: busca superar asimetrías e injusticias.

8. Investigación como espacio de formación y aprendizaje.

${ }^{6}$ TORRES, Alfonso. "Las complejidades de lo social y los desafíos a la investigación crítica". En: Cuadernos de sociología No. 36. Bogotá: USTA, 2000.
9. Fronesis: búsqueda de coherencia entre pensamiento y práctica.

Finalmente, quiero destacar las confluencias de los presupuestos de la investigación comprometida con las críticas contemporáneas al carácter colonial de las ciencias y con algunas de las ideas promovidas desde el posmodernismo progresista (tal como lo llamaron Fals y Freire).

En el primer caso, a partir de los planteamientos sobre orientalismo de Said y de las llamados estudios poscoIoniales de la India, un grupo de intelectuales latinoamericanos (algunos desde los países centrales), han generado la llamada teoría decolonial, que reivindica sus raíces, no en la tradición moderna occidental, sino en las prácticas culturales de resistencia de los pueblos colonizados y busca cuestionar y subvertir la presencia de la racionalidad y el poder colonial en diferentes prácticas de saber, de poder y de ser, que incluso se reconocen como alternativas ${ }^{7}$. Ya Fals Borda desde 1970 había denunciado junto con otros intelectuales latinoamericanos, el carácter colonialista y eurocentrista de las ciencias sociales y la necesidad de una ciencia propia, enraizada en la singularidad de las problemáticas de la región y en opciones alternativas.

Si bien es cierto que el llamado posmodernismo asumió la bandera de lucha contra los metarrelatos teóricos y políticos clásicos como el marxismo, también proporcionó algunas ideas y pistas metodológicas con potencial emancipador. Por ejemplo, desde el postestructuralismo, autores como Foucault, Deleuze, Guattari y Derridá, aportan claves de lectura para cuestionar el poder, el

${ }^{7}$ WALSH, Cateherine y otros. Indisciplinar las ciencias sociales. Quito: UASB y Ediciones Abya-Yala, 2002. 
capitalismo y la posibilidad de deconstruir los discursos hegemónicos.

En ese sentido, Orlando Fals Borda (1991 y 1995), al igual que Paulo Freire (2001), hablaron de un "posmodernismo progresista", para referirse a las convergencias entre la tradición emancipatoria latinoamericana expresada en la Educación Popular y la Investigación Acción Participativa y algunas de las ideas reivindicadas por autores contemporáneos que hacen críticas al capitalismo, enfatizan las relaciones entre poder, cultura y conocimiento, el reconocimiento del potencial emancipador de los saberes subalternos la reivindicación de la diferencia y de la política menor.

Para terminar, quiero retomar los planteamientos acerca de la que he denominado investigación de borde ${ }^{8}$ para caracterizar a la IAP y a la labor de intelectuales como Orlando Fals Borda. Investigar desde el margen, lo hemos entendido como un posicionamiento y una práctica de producción de conocimiento social, lle-

${ }^{8}$ TORRES, Alfonso."Investigar desde los márgenes de las ciencias sociales”. En: Revista Folios No. 27. Bogotá: Universidad Pedagógica Nacional, 2008. vada a cabo por sujetos (individuales, colectivos) que proviniendo de las ciencias sociales o no, transgrede en la racionalidad disciplinar dominante. En este sentido, lo marginal no es estar por fuera, sino en el umbral, en las fronteras: entre el adentro y el afuera, entre lo instituido y lo instituyente, entre lo conocido y lo inédito, entre lo determinado y lo indeterminado. Así, lo marginal abre nuevas posibilidades para

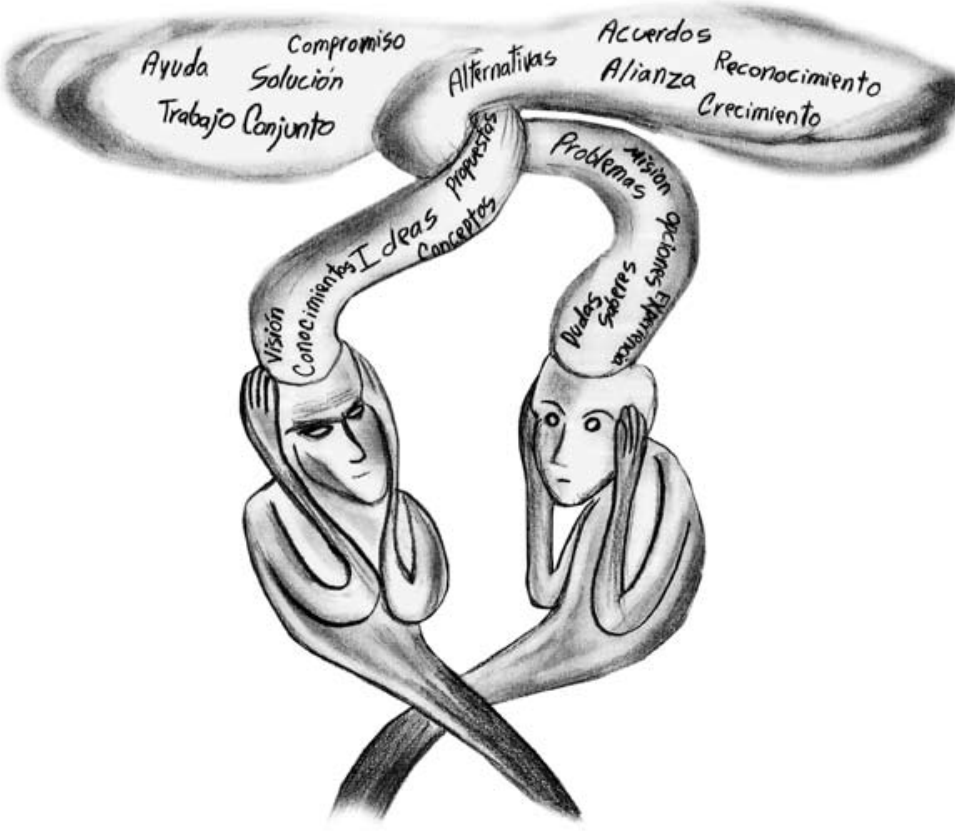
pensar, para imaginar, para construir nuevas realidades. Por otro lado, lo marginal, lo liminal, asumido no tanto como postura epistémica sino como posicionamiento ético y político, permite ver, decir y hacer lo que no es visible o factible desde el centro de las instituciones de conocimiento y poder.

Así como los "marginales", ponen en evidencia los límites y las arbitrariedades del orden social, la investigación liminal hace visible el agotamiento de las disciplinas sociales y de los epistemes institucionales para abordar y encauzar ciertas realidades constituyentes 9 . Es el caso de Fals Borda, quien habiendo sido educado dentro de la perspectiva funcionalista, tuvo que confrontar a un país convulsiona-

9lbid, pág. 66 
do por la violencia y signado por profundas injusticias. Frente a estas circunstancias, este investigador pronto asumió responsabilidades con programas y propuestas de acción social y política ${ }^{10}$. Desde allí procuró acuñar nuevas categorías y generar nuevas estrategias de acercamiento a la vida social, involucrando activamente a las poblaciones afectadas por los problemas que se investigaban, generando metodologías alternativas que permitieran comprender de otras maneras e involucrar otras miradas sobre los problemas de los que se ocuparon.

Por ello, podemos afirmar que la IAP corresponde a lo que algunos autores han llamado "perspectivas de borde" y otros "razonamientos de umbral" para referirse a formas de conocimiento social que resultan de búsquedas en espacios diferentes y con modalidades distintas. Para Emma León estas formas de razonamiento conducen a dos aspectos considerados cruciales: "Por un lado, encontrar nuevas facetas a los contenidos producidos y acumulados en esferas particulares del conocimiento, lo que implica ubicar tales contenidos más allá de los márgenes decantados por las teorías establecidas; por otro lado, y en relación estrecha con lo anterior, el operar fuera de estos márgenes les permite enfrentarse con la necesidad de abordar nuevas realidades, y construir conocimientos que respondan a ámbitos de sentido diferentes a los ya definidos"11.

Finalmente, la emergencia de estas modalidades investigativas también tiene que ver con la existencia de

\footnotetext{
${ }^{10}$ Orlando Fals Borda, al igual que el sacerdote Camilo Torres Restrepo, participó en las Juntas Directivas del Instituto de Reforma Agraria y el Departamento de Acción Comunal; a su vez, cada uno, por iniciativa personal, habían impulsado experiencias asociativas y movimientos de promoción social.

${ }^{11}$ ZÉMELMAN y LEON Emma. Subjetividad: umbrales del pensamiento social. Barcelona: Anthropos, 1997.
}

sujetos individuales y colectivos que las agencien, ¿quiénes son? Por un lado, intelectuales provenientes de la institucionalidad de las ciencias sociales (universidades y centros de investigación), quienes por sus opciones políticas o temáticas mantienen vínculos orgánicos con realidades extra-académicas. Asumir opciones políticas, éticas y epistemes disidentes, alternativas o de transformación social, plantea al trabajo intelectual la necesidad no sólo de enfrentarse a exterioridades prácticas más allá de la academia, sino a cuestionar las propias reglas de juego de la institucionalidad científica. Es lo que plantea Michel Maffesoli con su metáfora de nomadismo intelectual y desde el cual podemos definir a Fals Borda:

"De manera que la empresa que se inicia es libertaria. Hacer escuela es fácil y aburrido; es mucho más fecundo esforzarse por echar una mirada libre, a la vez insolente, ingenua, incluso trivial, en todo caso desagradable, pero que abre brechas y permite fuertes intercambios que los mercaderes y burócratas ni siquiera imaginan. Así pues, insolencia de pensamiento... Al trastornar el orden establecido de las cosas y las personas, el nomadismo se vuelve expresión de un sueño inmemorial que el embrutecimiento de lo instituido, el cinismo económico, la reificación social o el conformismo intelectual no llegan jamás a ocultar totalmente"12.

${ }^{12}$ MAFFESOLI, Michel. El conocimiento ordinario. México D.F., FCE Sociología, 1993, pág. 29. 


\section{Bibliografía}

FALS BORDA, Orlando. El problema de cómo investigar la realidad para transformarla por la praxis. Bogotá: Tercer Mundo editores, 1984.

, y ANISUR, Mohamad. Acción y conocimiento. Bogotá: Cinep, 1991.

Investigación Acción, ciencia y educación popular en los noventas. Taller Internacional La Habana: CEAAL, 1995.

FREIRE, Paulo. Pedagogía de la indignación. Madrid: Morata, 2001.

FRIED, Dora. Nuevos paradigmas: Cultura y subjetividad. Buenos Aires: Paidós, 1994.

GIBBONS y otros. La nueva producción del conocimiento. La dinámica de la ciencia y la investigación en las sociedades contemporáneas. Barcelona: Pomares, 1997.

LIPMAN, Matthew. Pensamiento complejo y educación. Madrid: Ediciones La Torre, 1998.

JIMÉNEZ, Absalón y TORRES, Alfonso. La práctica investigativa en ciencias sociales. Bogotá: Universidad Pedagógica Nacional, 2004.

MAFFESOLI, Michel. El conocimiento ordinario. México D.F.: FCE Sociología, 1993.

2005.

El nomadismo. México D. F.: Breviarios FCE.,
MIGNOLO, Walter. El pensamiento decolonial: desprendimiento y apertura. Un manifiesto. Mimeo (s.f.).

MORIN, Edgar. El método. Las ideas. Madrid: Cátedra, 1992.

Introducción al pensamiento complejo. Buenos Aires: Gedisa, 1996

SANTOS, Boaventura de Sousa. La caída del angelus novus. Ensayos para una nueva teoría social y una nueva práctica política. Bogotá: ILSA - Universidad Nacional de Colombia, 2003.

Renovar la teoría crítica y reinventar la emancipación social. Buenos Aires: CLACSO, 2006.

TORRES, Alfonso. Enfoques cualitativos y participativos de investigación social. Bogotá: UNAD, 1998.

"Las complejidades de lo social y los desafíos a la investigación crítica". En: Cuadernos de sociología No. 36. Bogotá: USTA, 2000.

. "Investigar desde los márgenes de las ciencias sociales". En: Folios No. 27. Bogotá: Universidad Pedagógica Nacional, 2008.

"Educación popular y nuevos paradigmas". En: La Piragua No. 28. Panamá: CEAAL, 2009.

VIO GROSSI, Francisco. "La investigación participativa: contexto político y organización popular". En: Arco Iris, Santiago de Chile: CEAAL, 1993.

WALLERSTEIN. Abrir las ciencias sociales. México: Siglo $\mathrm{XXl}, 1996$. 
$\mathrm{XXI}, 1998$

Impensar las ciencias sociales. México: Siglo

WALSH, Cateherine y otros. Indisciplinar las ciencias sociales. Quito: UASB y Ediciones Abya - Yala, 2002.

ZÉMELMAN, Hugo. Voluntad de conocer. El sujeto y su pensamiento en el pensamiento crítico. Barcelona: Anthropos y Centro de Investigaciones Humanísticas de la Universidad Autónoma de Chiapas, 2005.

y LEON Emma. Subjetividad: umbrales del pensamiento social. Barcelona: Anthropos, 1997. 